\title{
JCOM \\ Onto new horizons: insights from the WeObserve project to strengthen the awareness, acceptability and sustainability of Citizen Observatories in Europe
}

\section{Gerid Hager, Margaret Gold, Uta Wehn, Raquel Ajates, Linda See, Mel Woods, Chrysovalantis Tsiakos, Joan Masó, Dilek Fraisl, Inian Moorthy, Dahlia Domian and Steffen Fritz}

Abstract

Keywords

DOI

Introduction
WeObserve delivered the first European-wide Citizen Observatory (CO) knowledge platform to share best practices, to address challenges and to inform practitioners, policy makers and funders of COs. We present key insights from WeObserve activities into leveraging challenges to create interlinked solutions, connecting with international frameworks and groups, advancing the field through communities of practice and practitioner networks, and fostering an enabling environment for COs. We also discuss how the new Horizon Europe funding programme can help to further advance the $\mathrm{CO}$ concept, and vice versa, how COs can provide a suitable mechanism to support the ambitions of Horizon Europe.

Citizen science; Environmental communication; Public engagement with science and technology

https://doi.org/10.22323/2.20060201

Submitted: 30th October 2020

Accepted: 11th March 2021

Published: 11th October 2021

\subsection{Citizen Observatories in Europe}

Citizen Observatories (COs) can play an important role in addressing climate change, sustainable development, and other key issues by inviting the public to contribute observations, data and other 'in-situ' information to community-based environmental monitoring programmes, complementing authoritative and formal data sources for policy-making and environmental governance. They can also result in increased citizen participation in environmental management and governance at both a local and larger scale. COs are one of the key means by which communities can monitor and report on their environment and access information that is easily understandable for decision-making. In this way, COs form an approach to participatory research that falls within the wider field of Citizen Science (CS) [cf. Eitzel et al., 2017]. 
The term 'Citizen Observatory' was coined by Prof. Jacqueline McGlade in a 2009 Earthwatch Lecture entitled 'Global citizen observatory - The role of individuals in observing and understanding our changing world", wherein she stated that "it is no longer sufficient to develop passive lists or reports to 'inform' citizens of changes in our environment. We need to engage with citizens and ask how they can 'inform' us" [McGlade, 2009]. She called on Earth Observation (EO) systems such as Copernicus ${ }^{1}$ and SEIS $^{2}$ to obtain and use local knowledge for empowering citizens and to understand local requirements of sustainable development.

The concept of COs was taken up within the European Commission (EC), and described as combining EO technologies with tech-enabled and community-based environmental monitoring for delivering new data and information systems. These should empower communities and provide them with understandable information for decision-making [Mazumdar et al., 2016; Iglesias, 2013; Liu, Grossberndt and Kobernus, 2017]. Since then, a growing number of COs and CO projects ${ }^{3}$ have been supported via funding from the European Union's (EU) Seventh Framework Programme (FP7) and Horizon 2020 Programme (H2020), as shown in Table 1. These have covered a diverse range of environmental topics - such as soil health, biosphere monitoring, odour, air pollution, flood and drought monitoring, and coastal and marine water quality monitoring. These projects have also been further developing innovative EO technologies and applications that enable citizens to effectively participate in environmental stewardship and express the policy priorities of their community.

Table 1. COs funded by the EU via FP7 and Horizon 2020.

\begin{tabular}{|l|l|c|}
\hline $\begin{array}{l}\text { FP7-funded CO } \\
\text { projects }\end{array}$ & Focus & Timeline \\
\hline COBWEB & Biosphere monitoring & $2012-2016$ \\
\hline OMNISCIENTIS & Odour monitoring & $2012-2014$ \\
\hline CITI-SENSE & Air pollution monitoring & $2012-2016$ \\
\hline WeSenseIt & Flood and drought monitoring & $2012-2016$ \\
\hline Citclops & Coastal and marine water quality monitoring & $2012-2015$ \\
\hline $\begin{array}{l}\text { H2020-funded CO } \\
\text { projects }\end{array}$ & Focus & Timeline \\
\hline Ground Truth 2.0 & $\begin{array}{l}\text { Flood risk management, environmental quality of } \\
\text { tainable livelihoods, climate change adaptation }\end{array}$ & $2016-2019$ \\
\hline GROW Observatory & Soil, land-use, crop planting, and water resources & $2016-2019$ \\
\hline LandSense & Land use and land cover monitoring & $2016-2020$ \\
\hline Scent & Water supply \& quality, flood risks & $2016-2019$ \\
\hline D-NOSES & Odour monitoring & $2018-2021$ \\
\hline Monocle & Water quality monitoring & $2018-2021$ \\
\hline
\end{tabular}

Other funding calls in the H2020 programme have also supported the implementation of the $\mathrm{CO}$ concept, ${ }^{4}$ or the coordination and development of $\mathrm{CO}$

\footnotetext{
${ }^{1}$ Then known as "Global Monitoring for Environment and Security".

${ }^{2}$ Shared Environmental Information Systems.

${ }^{3}$ In this paper, we distinguish between ' $\mathrm{CO}$ projects' and 'COs'. CO projects refer to the specific, time-bound EC (or otherwise) funded projects to set up or support COs 'on the ground'.

${ }^{4}$ See e.g., calls SFS-1: farmland biodiversity or SC5-2017-18: novel in-situ observation systems.
} 
services..$^{5}$ Most recently, the H2020 European Green Deal call ${ }^{6}$ offers multiple opportunities for $\mathrm{CO}$ funding.

COs and their potential are being further explored and defined within the academic literature, which places COs in the context of environmental governance and emphasises their value to environmental management, decision-making and sustainable development. Liu, Kobernus et al. [2014] highlight different data collection tools, such as mobile phones, sensors and social media content, the role of the community and citizen's understanding of environmental issues and their participation in discussing them via information and communication technology (ICT) platforms, as well as two-way interactions and collaborative participation throughout. Other working definitions for COs emphasise the structural role of COs as an "information ecosystem" for diverse stakeholders to inform place-based actions [Ciravegna et al., 2013]. Grainger [2017] defined COs simply as "any use of Earth observation technology in which citizens collect data and are empowered by the information generated from these data to participate in environmental management" [Grainger, 2017, p. 4]. He also distinguished COs from CS in two main ways. COs provide a direct and practical benefit to citizens and society at large (as opposed to primarily benefiting science) and they mostly fall within the co-created or collaborative project categories (rather than within the contributory category) [cf. Bonney et al., 2009]. In another comprehensive treatment of the CO concept and CO projects existing at the time, Liu, Grossberndt and Kobernus [2017] propose a common model for COs. It builds on procedural aspects of realising a CO including the identification of citizens' needs and interests; citizen engagement; tool development for monitoring (data gathering) and decision-making (data interpretation); citizen and stakeholder networks; as well as the underlying ICT infrastructure.

The commonalities across these definitions and conceptualisations are the participation of citizens in environmental monitoring and governance, the bi-directional flow of data and information, the enhancement of EO systems with citizen-generated observations 'in situ', and the use of modern mobile and web technologies to do so. These elements highlight the complex nature of COs from a socio-technical perspective and provide a glimpse into the types of challenges that they may face in practice.

\subsection{The WeObserve project}

WeObserve ${ }^{7}$ was an H2020 Coordination and Support Action (CSA) (2017-2021) delivering the first European-wide $\mathrm{CO}$ knowledge platform to share and consolidate best practices and to identify and address challenges to inform practitioners, policy makers and funders of COs. WeObserve was informed by the vision that COs and community-based environmental initiatives are an integral

\footnotetext{
${ }^{5}$ See e.g., call INFRAEOSC-2019-1 and the COS4CLOUD project.

${ }^{6}$ https: / / ec.europa.eu/research/participants/data/ref/h2020/wp/2018-2020/main/h2020wp1820-cc- activities_en.pdf.

${ }^{7}$ http: / / www.weobserve.eu.

${ }^{8}$ Horizon 2020 is the EU Framework Programme for research and innovation (2014-2020) and consists of different types of funding actions. CSAs are accompanying measures such as standardisation, awareness-raising and communication, networking, policy dialogues or mutual learning exercises.
} 
component of managing environmental challenges, empowering communities in Europe to contribute to environmental stewardship. WeObserve brought together four CO projects, namely the four H2020 Innovation Actions: LandSense, Ground Truth 2.0, GROW Observatory, and Scent. ${ }^{9}$ Table 2 provides an overview of the four $\mathrm{CO}$ projects including a short description and their main goals.

Table 2. Overview of four CO projects funded under Horizon 2020 topic SC5-17-2015.

\begin{tabular}{|c|c|c|}
\hline Name, durati & Description & Main goals \\
\hline $\begin{array}{l}\text { LandSense } \\
\text { 2016-2020 } \\
\text { landsense.eu }\end{array}$ & $\begin{array}{l}\text { LandSense built a CO for } \\
\text { Land Use and Land Cover } \\
\text { (LULC) monitoring, by con- } \\
\text { necting citizens with EO } \\
\text { data to transform current } \\
\text { approaches to environmental } \\
\text { decision-making. }\end{array}$ & $\begin{array}{l}\text { The goal was to complement ex- } \\
\text { isting environmental monitoring } \\
\text { systems through EO-based mobile } \\
\text { and web applications, engaging } \\
\text { citizens to play a key role in LULC } \\
\text { monitoring, and to be directly in- } \\
\text { volved in the co-creation of such } \\
\text { monitoring systems and apps. }\end{array}$ \\
\hline $\begin{array}{l}\text { Gro } \\
2016 \\
\text { gt20 } \\
\text { gre }\end{array}$ & $\begin{array}{l}\text { Ground Truth } 2.0 \text { set up and } \\
\text { validated six individual COs } \\
\text { in real conditions, in four } \\
\text { European and two African } \\
\text { demonstration cases. }\end{array}$ & $\begin{array}{l}\text { The project aimed to demonstrate } \\
\text { that COs are technologically feas- } \\
\text { ible, can be implemented sustain- } \\
\text { ably and that they have societal, } \\
\text { environmental and economic be- } \\
\text { nefits. The ultimate objective was } \\
\text { improved global uptake of the } \\
\text { concept and the enabling techno- } \\
\text { logies. }\end{array}$ \\
\hline $\begin{array}{l}\text { GRC } \\
2016 \\
\text { grow }\end{array}$ & $\begin{array}{l}\text { The GROW Observatory cre- } \\
\text { ated a CS community of hobby } \\
\text { food growers and small-scale } \\
\text { farmers across Europe to gen- } \\
\text { erate, share and use inform- } \\
\text { ation on land, soil and wa- } \\
\text { ter resources at high- resolu- } \\
\text { tion through the use of low- } \\
\text { cost sensing technology. }\end{array}$ & $\begin{array}{l}\text { The goal was to underpin } \\
\text { technology-enabled and sus- } \\
\text { tainable custodianship of land } \\
\text { and soil, contributing to sus- } \\
\text { tainable food production, and to } \\
\text { address a long-standing challenge } \\
\text { for space science, namely the val- } \\
\text { idation of soil moisture detection } \\
\text { by satellites. }\end{array}$ \\
\hline 20 & $\begin{array}{l}\text { Scent created a toolbox of } \\
\text { smart technologies and ap- } \\
\text { plications for citizens to use } \\
\text { low-cost equipment to col- } \\
\text { lect various types of environ- } \\
\text { mental information, such as } \\
\text { LULC. }\end{array}$ & $\begin{array}{l}\text { The project aimed to improve } \\
\text { flood modelling, to offer citizen- } \\
\text { generated data to GEOSS } \\
\text { OGC }{ }^{11} \text {-compliant observations, to } \\
\text { enable citizens to monitor changes } \\
\text { and understand how they affect } \\
\text { flood phenomena in urban or rural } \\
\text { areas. }\end{array}$ \\
\hline
\end{tabular}

WeObserve initially identified three key challenges to be systematically addressed in order to facilitate the mainstreaming of COs. They emerged from early discussions sharing the project experiences of the four $\mathrm{CO}$ projects and were selected to provide a framework for reflecting on these experiences in greater depth. No comprehensive literature review was done at that time. These three challenges are:

\footnotetext{
${ }^{9}$ Funded in the programme H2020-EU.3.5.5. — Developing comprehensive and sustained global environmental observation and information systems under the topic SC5-17-2015 — Demonstrating the concept of 'Citizen Observatories'.

${ }^{10}$ Global Earth Observation System of Systems.

${ }^{11}$ Open Geospatial Consortium.
} 
1. Improving awareness of and engagement in COs and CS activities: Citizens are often unaware of opportunities to address and help monitor environmental issues. Likewise, public authorities, SMEs and NGOs are often unaware of the potential of COs to support decision-making and create business opportunities.

2. Increasing quality and acceptability and showcasing the added value for better uptake: COs and CS are often assumed to lack the required quality standards to generate insights for decision-making and environmental governance. Public authorities are hesitant to accept data from CS efforts to complement authoritative data.

3. Creating stable communities, infrastructures and transition processes that facilitate the sustainability of the $\mathrm{CO}$ and help scale up $\mathrm{CO}$ activities:

Although local and continent-wide projects have shown great promise, the existing processes, infrastructures, measures of success, and legislation are currently insufficient to sustain or scale up CS projects across various sectors. Deficiencies in transition governance, funding systems and standards of data preservation and data interoperability are limiting the long-term potential of CS and COs.

Table 3. WeObserve activities and the challenges they address; A: Awareness, AC: Acceptability, S: Sustainability.

\begin{tabular}{|c|c|c|c|c|}
\hline WeObserve activity & Description & $\mathbf{A}$ & $\mathrm{AC}$ & $\mathbf{S}$ \\
\hline $\begin{array}{l}\text { Communities of prac- } \\
\text { tice }\end{array}$ & $\begin{array}{l}\text { To consolidate and disseminate practice-based knowledge of } \\
\text { COs, sharing information and resources, and working to fur- } \\
\text { ther develop best practice guidelines and toolkits for COs }\end{array}$ & $\mathrm{x}$ & $\mathrm{x}$ & $\mathrm{x}$ \\
\hline $\begin{array}{l}\mathrm{CO} \text { landscape map- } \\
\text { ping and report }\end{array}$ & $\begin{array}{l}\text { To advance the understanding of the } \mathrm{CO} \text { concept and related } \\
\text { practices in Europe }\end{array}$ & $\mathrm{x}$ & $\mathrm{x}$ & $\mathrm{x}$ \\
\hline Events & To gather practitioners for knowledge sharing and discussion & $\mathrm{x}$ & $\mathrm{x}$ & $\mathrm{x}$ \\
\hline $\begin{array}{l}\text { Massive open online } \\
\text { course }\end{array}$ & $\begin{array}{l}\text { To share knowledge, promote learning and engage with an in- } \\
\text { ternational community of learners, from people new to CS, to } \\
\text { experienced citizen scientists and practitioners. }\end{array}$ & $\mathrm{x}$ & $\mathrm{x}$ & \\
\hline Roadshows & $\begin{array}{l}\text { To connect with authorities and environmental managers and } \\
\text { showcase the added value of COs for environmental risk and } \\
\text { disaster management }\end{array}$ & $\mathrm{x}$ & $\mathrm{x}$ & \\
\hline $\begin{array}{l}\text { WeObserve challenges } \\
\text { at the INSPIRE hacka- } \\
\text { thon }\end{array}$ & $\begin{array}{l}\text { To spur solution prototyping for CO and CS data integration, } \\
\text { cataloguing and authentication }\end{array}$ & & $x$ & $\mathrm{x}$ \\
\hline $\begin{array}{l}\text { Interoperability experi- } \\
\text { ment }\end{array}$ & $\begin{array}{l}\text { To identify best practices for CO data interoperability and the } \\
\text { application of data standards }\end{array}$ & & $\mathrm{x}$ & $\mathrm{x}$ \\
\hline Copernicus pilot & $\begin{array}{l}\text { To demonstrate the value of } \mathrm{CO} \text { data for the field of EO and } \\
\text { remote sensing }\end{array}$ & $\mathrm{x}$ & $\mathrm{x}$ & \\
\hline Open data challenge & $\begin{array}{l}\text { To promote and demonstrate the uptake of } \mathrm{CO} \text { data for the } \\
\text { development of downstream applications }\end{array}$ & & $\mathrm{x}$ & $\mathrm{x}$ \\
\hline $\begin{array}{l}\text { Policy briefs and pub- } \\
\text { lications }\end{array}$ & $\begin{array}{l}\text { To translate and highlight relevant findings and insights for } \\
\text { policy makers and funders, as well as to disseminate gathered } \\
\text { knowledge in the research field }\end{array}$ & $\mathrm{x}$ & $\mathrm{x}$ & $x$ \\
\hline WeObserve conference & $\begin{array}{l}\text { To increase the visibility of COs in Europe and showcase their } \\
\text { added value on multiple levels and across stakeholders }\end{array}$ & $\mathrm{x}$ & $x$ & \\
\hline Toolkit & $\begin{array}{l}\text { To gather best practice tools and methods from CO projects } \\
\text { and make them accessible to other CS/CO projects }\end{array}$ & & $\mathrm{x}$ & $\mathrm{x}$ \\
\hline Cookbook & $\begin{array}{l}\text { To provide guidelines for creating successful and sustainable } \\
\text { COs }\end{array}$ & $x$ & $x$ & $x$ \\
\hline
\end{tabular}


To advance the CO concept, highlight its impact potential and develop solutions to the identified challenges, WeObserve has facilitated the formation of new networks and knowledge-building activities by establishing communities of practice (CoPs) on different $\mathrm{CO}$ and CS-related topics: co-design and engagement, impact, interoperability, and on CS and the UN Sustainable Development Goals (SDGs). Additionally, WeObserve has created a massive open online course (MOOC) and has conducted data and infrastructure interoperability experiments. Table 3 outlines the full range of WeObserve activities, and the challenges they aimed to primarily address.

\subsection{Aims and structure of the paper}

This paper offers insights and lessons learned about COs in the European funding context, based on the experiences of four $\mathrm{CO}$ projects, collated by the WeObserve project. Section 1 provided the background to COs in Europe and an introduction to WeObserve. Section 2 describes methods and sources used to collect and synthesise experiences and knowledge across the four $\mathrm{CO}$ projects. Sections 3-5 present results on $\mathrm{CO}$ outcomes and impacts (section 3), challenges (section 4) and overarching lessons learned (section 5). Section 6 discusses opportunities for COs in future funding calls, such as Horizon Europe, and includes recommendations for funding bodies to further advance the $\mathrm{CO}$ concept. Section 7 provides conclusions.

\section{Methods to explore challenges, highlight impact and develop solutions}

WeObserve carried out a wide range of knowledge creation, sharing, and consolidation activities (see section 1.2) with consortium members, relevant stakeholders and the wider CO and CS community to capture insights and recommendations to overcome $\mathrm{CO}$ challenges and maximise their impacts. The findings presented in this paper mainly draw on and synthesise insights from the following sources and activities.

The WeObserve Landscape Report on Citizen Observatories in Europe presents an in-depth assessment of persistent challenges and best practices from $9 \mathrm{CO}$ legacy projects from FP7 and H2020. The report is provided in two parts [Gold, 2018; Gold, Wehn et al., 2020] and is based on multiple methods and sources. A literature review on COs was undertaken to select suitable frameworks to describe, assess and compare $\mathrm{CO}$ projects. The evaluation of $\mathrm{CO}$ projects for the reports used a composite framework and derived insights into the topics of awareness, acceptability and sustainability of COs. In addition to the literature review and harvesting insights from event (1) described below, data were gathered through 12 face-to-face interviews with key $\mathrm{CO}$ project initiators and stakeholders, from the work of the CoPs, and various other WeObserve events.

The following three WeObserve events specifically addressed and helped to elicit challenges in different contexts as well as to develop recommendations to overcome them.

1. Observing the Environment: Challenges and Opportunities in Citizen Science: this knowledge exchange event at the EC in Brussels in October 2019 was attended by $43 \mathrm{CO}$ and CS practitioners as well as representatives from the 
EC. Experiences around raising awareness, promoting acceptability and ensuring sustainability of COs were addressed in breakout groups.

Recommendations on how to overcome them were discussed in a joint fishbowl discussion and the main insights documented in a report [Domian and Hager, 2019].

2. Citizen Science working session in the EuroGEO Workshop 2019: this event in July 2019 brought together the community of CO and CS practitioners, as well as key collaborators and led to the formulation of the Lisbon declaration [Masó and Fritz, 2020], a roadmap document, that summarises the current state of $\mathrm{CS}$ in $\mathrm{GEO}^{12}$ and GEOSS. The roadmap also proposes a vision, objectives, concrete actions as well as recommendations to the EC to improve the integration of CS and CO activities and datasets into GEO and GEOSS.

3. Workshop on citizen science and the SDGs: the event was held at the International Institute for Applied Systems Analysis in October 2018 and was attended by representatives from CS associations, researchers, CO/CS practitioners, and UN agencies. It kicked off longer-term discussions on how CS can be integrated into SDG monitoring and implementation. At the workshop, the WeObserve SDGs CoP was formally launched. Amongst others, two journal papers on the potential of COs and CS for SDG monitoring stem from these activities [Fritz et al., 2019; Fraisl et al., 2020].

Other outputs from the four $\mathrm{CO}$ projects and the WeObserve project were used to identify and gather realised and emerging impacts (section 3) as well as to complement the recommendations for future funders and initiators of COs (section 5). These materials include 13 project deliverables (technical reports as well as reports with dedicated CO impact analyses) [Capellan, 2020; GROW, 2020a; GROW, 2020b; Moorthy et al., 2020; Mrkajić, 2020; SCENT, 2020a; SCENT, 2020b; SCENT, 2020c; Wehn, Pfeiffer, Gharesifard, Anema et al., 2017; Wehn, Gharesifard, Anema et al., 2019; Wehn, Gharesifard and Bilbao, 2020; Wehn, Pfeiffer, Gharesifard, Alfonso et al., 2020; Woods, Ajates et al., 2019], three academic (conference) papers on the impacts of selected COs [Assumpção et al., 2019; Gharesifard, Wehn and van der Zaag, 2019; Tsiakos et al., 2019], the WeObserve policy brief on creating sustainable COs [Gold and Wehn, 2020] and the WeObserve policy brief summarising the Lisbon Declaration [Masó and Wehn, 2020], as well as other briefs that discuss policy links and CO impacts [LandSense et al., 2018; LandSense, 2019].

Realised changes and emerging impacts
This section presents our synthesis of the realised changes and emerging impacts in the four CO projects. When considering the impacts of COs, it is helpful to distinguish between the concrete outputs achieved and their use or application, which may lead to intermediate outcomes or even long-term impacts which often lie beyond the immediate sphere of influence of the CO [Van Es, Guijt and Vogel, 2015]. An outcome can consist, for example, of a change in behaviour, relationships, actions, activities, or practices of an individual (micro level), of a group, community, or organisation (meso level), or of changes in policy (macro level) and lead to long term impacts and lasting changes. To illustrate, we summarise a range

\footnotetext{
${ }^{12}$ Group on Earth Observation.
} 
of realised changes and emerging impacts achieved by the $\mathrm{CO}$ projects (LandSense, Ground Truth 2.0, GROW Observatory, and Scent) by the end of 2019.

LandSense. Several COs were set up within the LandSense project in three cities (Vienna, Toulouse and Amsterdam), two regions (Vojvodina, Serbia and Flores Island, Indonesia) and one country (Spain) to enhance low-cost methods for acquiring high quality in-situ data to create timely, accurate and well-validated environmental monitoring products.

The urban COs were focussed on engaging citizens in collecting data on different aspects of land cover, land use and landscape change. Working with the French national mapping agency (IGN), the Paysages application was developed. It was used in combination with the LACO-Wiki online land cover validation tool to engage citizens to validate, correct and enrich IGN's LULC map of Toulouse and the surrounding area. Workflows were set up in which the citizen-collected data were used in an automated and more cost-effective way than using professional surveying. In Amsterdam and Vienna, citizen-generated information on greenspaces and other locations were provided to city planning authorities in rethinking the organisation of their greenspaces. The CO set up in Vojvodina, Serbia, was focussed on a young, digital friendly group of farmers to explore how EO can provide additional information to aid farming practices. The CropSupport app was developed in which farmers digitised their fields and shared cropping and management information. In exchange, they received EO-based advice on vegetation status, and learned about the potential of EO-based technologies. The regional authorities were interested in it for obtaining information on agricultural practices in a cost-effective way, while also preparing for Serbia's entry to the EU and the Common Agricultural Policy. The COs in Spain and Flores Island, Indonesia, are community-based biodiversity threat monitoring initiatives. The Natura Alert web and mobile app allows BirdLife volunteers to report threats, particularly those occurring within Important Bird and Biodiversity Areas (IBAs), and to facilitate the annual assessment of IBAs for international reporting, previously undertaken as a paper-based exercise. This greatly enhanced the current threat database and facilitates better decision-making through a user-friendly, citizen-driven monitoring solution. The solution will be transferred to Greece and Argentina in 2021, demonstrating a sustainable CO component.

Ground Truth 2.0. Developing and validating a co-design methodology, the Ground Truth 2.0 project set up demand-driven COs with relevant local stakeholders in six demonstration cases in Europe and Africa in different operational and cultural conditions. The resulting COs achieved progress to differing degrees towards the respective social and institutional outcomes that can lead to the envisioned longer-term environmental impacts. Changes achieved were highly case-specific.

The Meet Mee Mechelen CO in Belgium aimed to improve air quality and reduce noise. The collection of missing data by citizens, and the online platform for the interpretation of this data changed the overall access to and control over air quality data. The $\mathrm{CO}$ was also recognised by politicians and the media, creating new possibilities for public involvement and additional ways of influencing public opinion by providing evidence and data as a "bargaining chip". The Grip of Water 
$\mathrm{CO}$ in the Netherlands wanted to limit damage by pluvial flooding in urban and rural areas, integrating many publicly available data sources (weather, flood measures, water levels). The formal engagement of citizens in the work of the municipality and water board did not change but, informally, valued connections were made. Participating citizens started to 'green' their garden as a concrete preventative flood measure. RitmeNatura in Spain intended to improve the adaptation of natural areas to climate change. Citizens involved in collecting phenological observations improved their awareness on the impacts of climate change in their local environment. VattenFokus in Sweden on improving water health triggered citizens to consider their own lifestyle and consumption patterns, providing the basis for longer term behavioural change (e.g., reduced meat consumption). The CO offered opportunities to learn about the scientific aspects of water quality monitoring, enabling citizens to communicate about it with other community members and organisations. The Maasai Mara CO in Kenya promoted sustainable livelihoods and biodiversity. The stakeholders involved changed from being uninterested in working together to acknowledging their mutual interest and harmonious group interactions. Also, community members became more aware of their potential to influence authorities, while several authorities understood the importance of conservation. The National Community-based Natural Resource Monitoring Observatory in Zambia aimed to reduce illegal logging and increase wildlife numbers. While community participation in natural resources management (NRM) in Zambia is fully formalised, rights and entitlements of communities are not respected and the efforts to participate in NRM exceed the resources and capacities of most communities. The primary contribution of this $\mathrm{CO}$ was better support for local participation in NRM and access to information.

GROW Observatory. The GROW Observatory was focused on soil and regenerative food growing practices and demonstrated how CS data can interoperate with data collected from traditional scientific programmes such as GEOSS and improve current EO capabilities. For the first time in science, citizen-generated data from low-cost sensors were used to validate soil moisture information from Sentinel-1 satellites, which in turn will help improve the accuracy of predictions of extreme events. 24 GROW Observatory communities in 13 European countries created an unprecedented network of 6,502 soil sensors and a dataset of 516M rows of soil data [Woods, Cobley and GROW consortium, 2020]. It established the first continental-scale $\mathrm{CO}$ to monitor a key parameter for science, continuously over an extended period, and at an unmatched spatial density [Xaver et al., 2019; Zappa, Forkel et al., 2019; Zappa, Woods et al., 2020]. In addition, Ajates, Hager et al. [2020] demonstrate how the GROW Observatory contributed activities in support of achieving several SDGs at goals and target level, and how the CO could have potentially contributed to SDG monitoring, at indicator level.

Whilst a ubiquitous soil moisture dataset was generated across geographic zones, different changes and outcomes emerged in participant communities. In the Canary Islands, some participating farmers reduced irrigation water use by about 30\%, the Local Department of Agriculture also became involved, installing 123 sensors across nearly all the inland's climate zones. In Greece, a participating forestry commission explored combining GROW Observatory data with geographic information system (GIS) data to monitor a Natura $2000^{13}$ wetland to

\footnotetext{
${ }^{13}$ Natura 2000 is a network of nature protection areas in the EU.
} 
inform conservation policies for migratory birds. In Luxembourg, the forestry and nature administration distributed over 300 soil sensors to foresters across the whole country to create a robust coverage of soil data humidity and temperature which they could integrate into an ongoing study to inform forest conservation and management policies.

The soil sensing activities also triggered several bottom-up open science and innovation initiatives, networks and knowledge exchange activities within and across GROW Places, including using GROW Observatory data on no/tillage experiments, participants sharing their sensor data on GitHub or creating new open source apps. Growers also contributed to the validation of the Edible Plant Database, which offers growing advice and location-specific planting and harvesting dates for 140 edible plants across 12 European climate zones via sharing their growing activities in a Facebook group. By October 2019, 2,741 data submissions from 130 people/groups were received and used to improve the accuracy of the information provided.

Scent. The Scent CO established a toolbox of smart collaborative technologies and applications [SCENT, 2020d], enabling citizens to monitor changes in LULC and how these affect flood phenomena in their urban or rural areas and to enable and increase the involvement of citizens and citizen groups in environmental monitoring.

Several CS campaigns took place in the Kifisos River basin (Greece) and Danube Delta (Romania), over 11 months and resulted in the collection of more than 24,200 observations. Citizens collected various environmental data, including LULC elements, river parameters (water level and flow velocity) and soil measurements (soil moisture and air temperature). The project demonstrated how CS data can be integrated with EO through machine-learning to create actionable knowledge for participatory governance and policy making. The data were consolidated to improve flood modelling in support of preparedness and prevention actions. Furthermore, more accurate and updated local maps of LULC allowed policy makers to better face planning challenges linked to climate change and water management. They were offered to several national repositories and GEOSS as OGC-compliant observations, harmonised by applying novel protocols (i.e., OGC Sensor Things API). The project augmented and extended the in-situ component of GEOSS and Copernicus initiatives and improved the value of CS communities and Scent data from local to global scale.

Scent promoted new models of environmental governance by building on regional environmental groups and public-private partnerships, and by creating new active citizen communities for land-use monitoring. More than 700 citizens participated in the project's field campaigns and over 12,000 used the Scent mobile and web applications. The toolbox facilitated the engagement of citizens and volunteer associations in environmental decision-making, supported the democratic processes in public administration and improved the governance and application of EU and global environmental policy objectives. 
Table 4: Examples of micro-, meso-, and macro-level changes promoted through COs.

\begin{tabular}{|c|c|}
\hline \multicolumn{2}{|r|}{ Micro level changes } \\
\hline LandSense & $\begin{array}{l}\text { - Increasing awareness of urban and greenspaces through exploring and re- } \\
\text { porting on the urban environment } \\
\text { - New awareness of EO-based technologies to improve farming practices } \\
\text { - Increased reporting of threats in IBAs in Spain and Indonesia by citizens }\end{array}$ \\
\hline $\begin{array}{l}\text { Ground } \\
\text { Truth } 2.0\end{array}$ & $\begin{array}{l}\text { - Improved access to and control over data (e.g., air quality, water levels, phen- } \\
\text { ology, biodiversity, meteorology, or livestock) } \\
\text { - Citizens gained awareness of environmental issues (e.g., air polluters, cli- } \\
\text { mate change) } \\
\text { - Changes in damaging practice (greening gardens; consumption) }\end{array}$ \\
\hline GROW & $\begin{array}{l}\text { - Farmers in Spain reduced water use by } 30 \% \\
\text { - Use of soil moisture data to assess different low and no tillage methods } \\
\text { - Exploration of potential combination of sensor data with migratory bird be- } \\
\text { haviour data to gain insights on how soil moisture affects feeding and mi- } \\
\text { gratory patterns } \\
\text { - Farmers in the Netherlands started taking their own soil moisture data to } \\
\text { meetings with the local water authority }\end{array}$ \\
\hline Scent & $\begin{array}{l}\text { - Citizens gained awareness of how LULC changes affect flood phenomena in } \\
\text { their urban or rural areas }\end{array}$ \\
\hline \multicolumn{2}{|r|}{ Meso level changes } \\
\hline LandSense & $\begin{array}{l}\text { - Recognition by agencies involved in urban planning, mapping, agriculture } \\
\text { and biodiversity monitoring of the benefits of citizen engagement and in the } \\
\text { generation of valuable, low cost in-situ data } \\
\text { - Improved information products, e.g., enhanced land use/land cover map in } \\
\text { France }\end{array}$ \\
\hline $\begin{array}{l}\text { Ground } \\
\text { Truth } 2.0\end{array}$ & $\begin{array}{l}\text { - COs as a new means for institutional practice (e.g., stakeholder consultation) } \\
\text { - Improved disaster \& risk monitoring and management (floods) }\end{array}$ \\
\hline GROW & $\begin{array}{l}\text { - Increased networks and knowledge exchange activities within and amongst } \\
\text { the members of GROW Places in } 13 \text { European countries and other GROW } \\
\text { Observatory stakeholders }\end{array}$ \\
\hline
\end{tabular}

Continued on the next page. 
Table 4: Continued from the previous page.

\begin{tabular}{|c|c|}
\hline Scent & $\begin{array}{l}\text { - Formation of new active (online) citizen communities for land-use monitor- } \\
\text { ing } \\
\text { - Involvement of regional environmental groups and public-private partner- } \\
\text { ships } \\
\text { - Improved flood models tested for decision-making }\end{array}$ \\
\hline & Macro level changes \\
\hline LandSense & $\begin{array}{l}\text { - Lowered expenditure costs on in-situ data collection via unpaid contribu- } \\
\text { tions by citizens } \\
\text { - Current land-related databases improved, enhanced and validated, facilitat- } \\
\text { ing better decision-making } \\
\text { - Enhanced contributions to international biodiversity reporting }\end{array}$ \\
\hline $\begin{array}{l}\text { Ground } \\
\text { Truth } 2.0\end{array}$ & $\begin{array}{l}\text { - Shifts to preferred communication channels between citizens and authorities } \\
\text { - Changes in citizens' role in decision-making } \\
\text { - Support for implementation of policy through strengthened capacity \& ac- } \\
\text { cess to information }\end{array}$ \\
\hline GROW & $\begin{array}{l}\text { - Improved accuracy of predictions of extreme weather events } \\
\text { - User/integration of GROW Observatory data to inform conservation policies } \\
\text { - Improved scientific knowledge (soil moisture) } \\
\text { - Improved level of accuracy of edible plants database } \\
\text { - Shared sensor data on GitHub, new open source apps } \\
\text { - Contributions to achieving SDG goals and targets }\end{array}$ \\
\hline Scent & $\begin{array}{l}\text { - Augmented and extended the in-situ component of GEOSS and Copernicus } \\
\text { - Improved knowledge for diverse planning challenges linked to climate } \\
\text { change and water management }\end{array}$ \\
\hline
\end{tabular}

The individual COs established in the four $\mathrm{CO}$ projects have seen a wide range of changes and emerging impacts, many of which had already been realised during the projects' lifetime (see Table 4 for illustrative examples). At the micro level, we see specific examples of individual behavioural change and citizen empowerment through participation and data access. At the meso level, we see changes in institutional practice through the formation of new communities; we also see reported lower expenditure costs on in-situ data collection by authorities and improvements in risk monitoring and management. Finally, at the macro level, there is evidence of enhanced or new dialogues among key stakeholders (e.g., between citizens and authorities) of improvements to scientific knowledge, EO ground-truthing and augmentation of the in-situ component of GEOSS, and of improved and standardised services and decision-making tools. These outcomes provide a basis for longer lasting impacts which take time to fully emerge. For 
example, in all cases the COs have likely contributed with their activities to achieving the SDGs (goals and targets), as demonstrated in detail for the GROW Observatory [Ajates, Hager et al., 2020].

\section{Challenges}

COs can bring about important changes at a local, national and European scale, and engage local communities to benefit from the integration of new $\mathrm{CO}$ data and knowledge. However, there are also a range of challenges that COs face in practice. In this section we present the challenges experienced by the four $\mathrm{CO}$ projects in more detail within the three core areas of awareness, acceptability, and sustainability (see section 1.3), and the ways in which they have addressed them in practice.

Starting with a brief exploration of the CS literature on the topic of our three challenge areas, we find that acceptability issues around data quality and policy relevance are well documented and apply equally to COs and how WeObserve treated this topic [Anhalt-Depies et al., 2019; Gabrys, Pritchard and Barratt, 2016; Hecker et al., 2019; Roman et al., 2017; Serret et al., 2019]. While insights have started to emerge about the awareness of CS at the policy level [Hecker et al., 2019; Manzoni et al., 2019], much of the academic literature relates to citizen's awareness and knowledge about specific environmental issues or scientific literacy [Locritani, Merlino and Abbate, 2019; Mahajan et al., 2020], and not to their awareness of the opportunity to participate in, or capitalise on CS projects. The topic of sustainability in the CS literature is commonly associated with CS contributions to sustainable development, environmental management and ecological sustainability [see e.g. Fritz et al., 2019; Liu and Kobernus, 2017; Sauermann et al., 2020]. The sustainability of the COs themselves is less well represented, where sustainability refers to their ability to secure longer-term financial support, maintain technical infrastructures and keep communities engaged and active as well as the necessary factors to be able to do so.

\subsection{Awareness challenges}

Raising awareness about the opportunities to participate in $\mathrm{CO}$ initiatives as a citizen and to help gather vital environmental data for tackling local issues, is most often a communications challenge. COs struggle to rise above the noise of (social) media saturation and competing calls-to-action on related issues. It can be difficult to draw the attention of potential participants, to highlight what concern or need the $\mathrm{CO}$ is addressing, and how they relate to people's own motivations and interests. Additionally, some communities can be particularly hard to reach. Common science communication and engagement channels - from museums, science centres, or popular science newscasts - tend not to reach under-served and underrepresented communities as effectively. Specific focus and efforts are required to 'go where people are' to find places for interaction, understand their needs and motivations, and engage with potential gatekeepers of the community. COs that are addressing issues with generally low awareness amongst the public (e.g., soil health or odour pollution) face the additional challenge of clearly communicating what might be perceived as a niche concern. Furthermore, the ongoing effort to maintain an active community over the long-term, such that participants accept both the premise and the operational approach of the $\mathrm{CO}$ and 
get value out of participating regularly, is even greater than the effort needed to attract an initial group of participants. Reaching out to communities already aware of the issues was key in many of the COs, which resulted in a smaller initial group of participants, but it allowed for deeper engagement and provided the success stories that could be built upon.

The overall top-down approach in the four $\mathrm{CO}$ projects, due to the nature of the funding and the consortium formed around the primary objectives of each $\mathrm{CO}$, also meant that engagement with public authorities and other key stakeholders was built in from the start of each project. Nonetheless, awareness of CS and CO approaches was still low amongst these stakeholders or characterised by a narrow understanding of the potential of CS/COs (e.g., as a cheaper way to gather data). Achieving buy-in amongst key stakeholders was challenged by the difficulty of coming to a shared understanding of the $\mathrm{CO}$ approach, or a lack of shared vocabulary to describe the goals of the project. These difficulties were sometimes exacerbated by a lack of resources on the side of public authorities, holding them back from engaging fully. Co-design approaches, as followed in some of the COs, were even further outside the experience of policy makers. Tensions sometimes emerged between the need for flexibility within the process and the desire for a pre-defined course of action by the policy stakeholders, in order to secure resources. These tensions had knock-on effects for the acceptability and sustainability of the COs. Flexibility in co-design also meant that the citizen stakeholders engaged in the process could take the $\mathrm{CO}$ in a different direction from that originally envisioned. Hence, a shift in the communication paradigm for co-design processes from 'broadcast' towards facilitation was crucial to building deeper engagement towards a collaborative examination of the environmental issues and joint approaches to address them.

\subsection{Acceptability challenges}

Beyond the acceptability of the data itself, for which many data quality assurance measures have now been developed in CS [see for example Wiggins et al., 2011], acceptability issues in a CO can also arise around the ownership of the data, and around the ability of the $\mathrm{CO}$ to bring about the desired changes or impact without compromising the ethos of the $\mathrm{CO}$. These concerns include the need to address privacy and security issues regarding personal, or personally identifiable data (e.g., location data), the importance of tracing citizen-based contributions such that correct credit can be given, and the fear that the data might be 'sold' to commercial interests. Transparent data management measures and procedures, and open communication must be established up front. Failing to address these concerns can sufficiently affect the trustworthiness of an entire project. The theme of trust emerged as central to the challenge of acceptability across the various workshops and interviews - sometimes due to different mindsets and perspectives, and sometimes due to underlying tensions between the needs and motivations of the various parties.

These tensions can be illustrated by a triangle that must stay in balance between citizen participants, decision makers such as policy makers and public authorities, and the scientists leading or supporting the initiative. The image of the triangle (Figure 1) first emerged during the Observing the Environment: Challenges and 
Opportunities in Citizen Science knowledge exchange event in Brussels and became termed the 'Triangle of Trust' by the participants of the event.

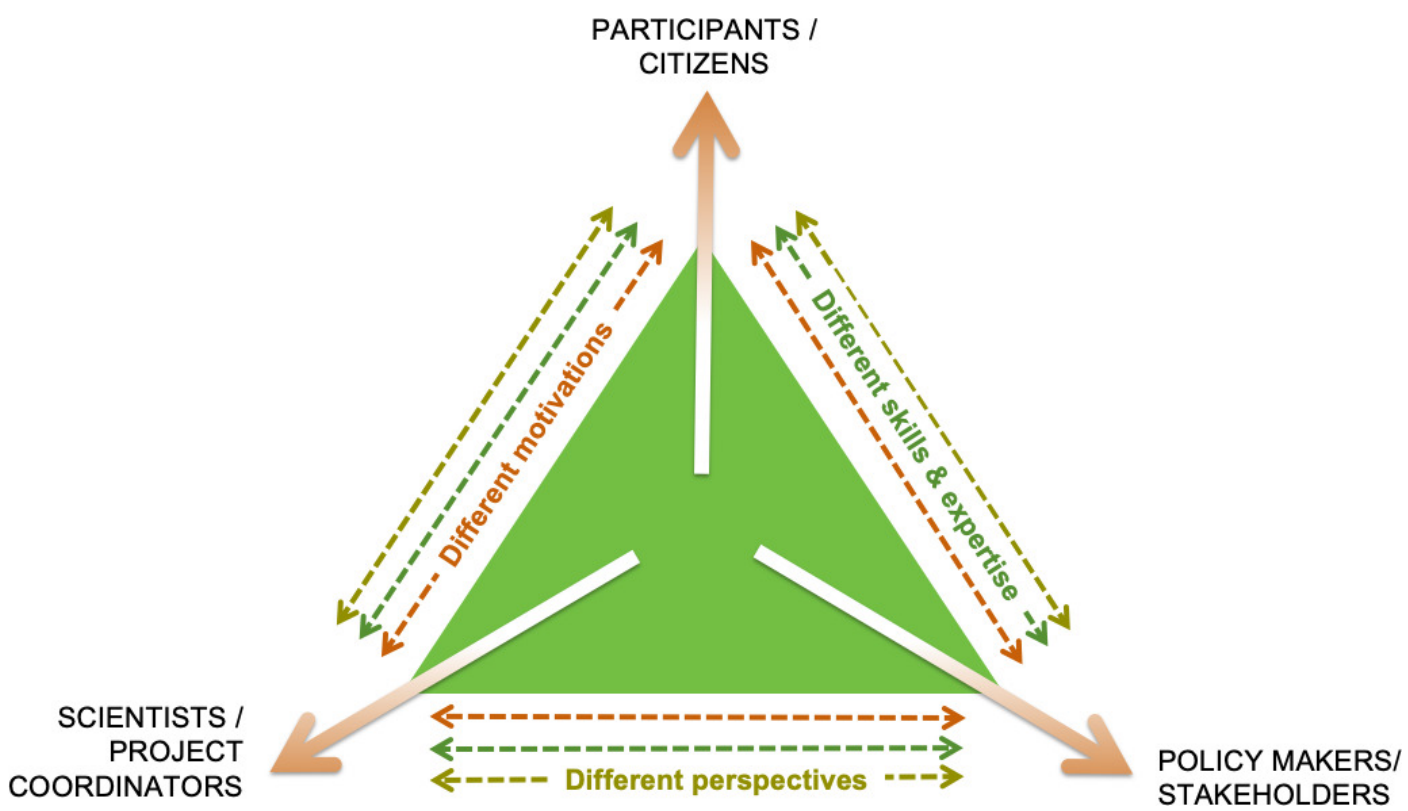

Figure 1. The 'Triangle of Trust', illustrating potential tensions that can emerge in a CO, complementing the triangular illustration of the Ground Truth 2.0 Concept [Wehn, Pfeiffer, Gharesifard, Anema et al., 2017].

Experience from the COs suggested that constant and consistent stakeholder engagement, with co-created inputs at key stages of the project lifecycle, are vital to keeping the triangle in balance. A similar balance must be struck between the social dimensions and community needs of the $\mathrm{CO}$, and the use and development of any underlying data gathering technologies such as sensors or other hardware. These can sometimes be in conflict with each other, calling the acceptability of the measurement tool into question, which must be fit for purpose with clear protocols, but also easy to use. To address these tensions, it is important to understand the forces exerting themselves on the 'Triangle of Trust' - different understandings of the problem and the solution, different motivations, different needs and goals, but also different skills and expertise. These tensions play out across all stakeholder relationships, and are highly specific to the nature and context of each $\mathrm{CO}$. The experience of one $\mathrm{CO}$ was that trust grew and mindsets shifted as data started to accumulate and first outcomes became apparent. These showed both the value of that data and a 'return on effort' from the participants, creating a reinforcing cycle for a more engaged and informed community of stakeholders. However, the experience of other COs has been quite the opposite, especially when authorities realise the full scale of potential changes involved, not all of which are necessarily welcomed or valued [Wehn, McCarthy et al., 2015].

\subsection{Sustainability challenges}

The themes that emerged on the sustainability of COs primarily relate to the operational, organisational, and governance continuity of COs, and the importance of planning for these right from the outset. By nature, these challenges often arise 
on the intersection of the funded $\mathrm{CO}$ projects (with a predefined timeline and budget) and the COs they try to establish 'on the ground'.

The reliance of most COs on an underlying technological tool such as a mobile application, sensors and monitoring devices, or a data aggregation platform, introduces a unique range of challenges. Some COs discovered that they have under-budgeted for ongoing application development in response to user feedback and the experience of the first demonstration cases. Others have had a key technology partner leave the project, either for commercial reasons or the non-viability of the technology. Additional technology risks can stem from the unsuccessful calibration of low-cost sensors in comparison to formal high-tech sensors, necessitating a change in methodology, or interoperability issues that prove insurmountable. And at the end of a project, failure to plan for technology transfer can leave a CO community without technical support. All of these risk factors require sufficient budget, contingency planning, and succession planning for ongoing hosting, maintenance, and development. Similar succession planning is needed for how the community can maintain momentum once the consortium-based project disperses. The timeline over which COs are able to build up community, gather the relevant data and deliver real change can often extend beyond the end of the pre-defined project funding period. Tensions can arise from different expectations about how the CO should be sustained, and by whom. This requires efforts for governance handover to build and keep the community, and alignment across the 'Triangle of Trust' in recognition of differing needs and motivations. Where pressures to seek commercial exploitation or monetisation of the data or the technology platform exist, issues of ownership and institutional embedding will also need to be addressed. It can be challenging to reach agreement amongst all actors on what the ambition and scope of the $\mathrm{CO}$ should be post-funding. This tension can arise in particular between science and policy actors, where different objectives may be at play. This is important to address because of the key role that policy makers can play in identifying local and national opportunities for further funding, especially in line with defined national environmental and societal policy goals.

Securing sources of financial support is one of the most important factors in enabling the continuation of COs because it can provide the means to address other issues such as ensuring ongoing infrastructure. But other supportive measures are also important, such as legislation aimed at either sustaining or scaling-up current $\mathrm{CO}$ projects across various sectors.

Lessons learned to address $\mathrm{CO}$ challenges and maximise impact
As highlighted in the previous sections, WeObserve has brought together insights from four $\mathrm{CO}$ projects for rich, practice-based learning. This section summarises and highlights the main factors that can support the implementation of future COs.

Acknowledging the evolution of the $\mathrm{CO}$ concept. While an updated treatment of the $\mathrm{CO}$ concept and its operational models is now pending in the literature, the experiences of the $\mathrm{CO}$ projects described in this paper highlight that the $\mathrm{CO}$ concept shows diverse manifestations and has been evolving over time. Outside of Europe, COs are often seen as a European construct that does not have an obvious analogue elsewhere. This became clear during discussions in several WeObserve 
CoP meetings. At the same time, COs begin to move beyond being considered a mere 'European artefact' within CS. More and more, COs represent a specific and unique form of CS, highlighting the combination of the environmental dimension with societal relevance and impact as well as including policy makers as important stakeholders (Figure 2). COs originated as a top-down concept put forward by the EC in FP7 and H2020 funding calls, and they range across all CS models from contributory to collaborative to co-designed. At least one of the projects that started with a contributory character evolved into more collegial endeavours [Ajates, Woods et al., 2020], combining the place-based, and bottom-up power of communities with low-cost sensing technologies to achieve local innovation and environmental monitoring at scale.

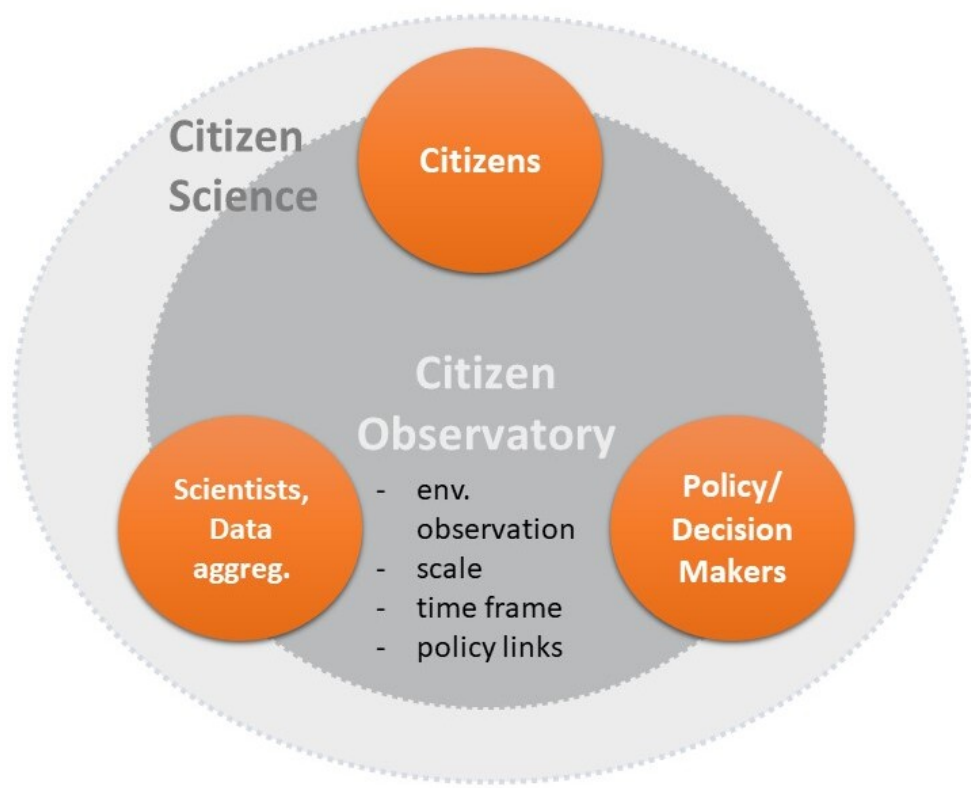

Figure 2. COs as a subset of CS, CoP Launch Workshops in Geneva, 2018 [Wehn, 2018].

COs have emerged more clearly as a diverse, but particular form of CS, that builds on place-based participation of citizens, employs web and mobile applications and focuses on environmental monitoring, management and governance. COs aim at societal relevance beyond science and facilitate actions across a network of stakeholders including citizens, citizen organisations, policy and decision makers, scientists and data aggregators. They build on the multi-directional flow of data and information and they are planned for longer-term, or a defined timeframe to address a specific issue/situation. Furthermore, we can observe a range of $\mathrm{CO}$ models with both top-down and bottom-up characteristics. We also see evidence for transitions from one such model, or modus operandi, to another, as well as their parallel implementation, depending on the respective $\mathrm{CO}$ activities.

Leveraging challenges to create interlinked solutions. If future COs can recognise that many of the key challenges are tightly interlinked and deliberately address them in an integrated way, they can create a cycle of positive reinforcement, where progress with addressing one factor can likely trigger improvement of the others (Figure 3). For example, if practitioners and projects can build awareness and demonstrate the value of their $\mathrm{CO}$ and related activities from the start, they make strides towards its uptake and sustainability. Likewise, if 
aspects of data acceptability are addressed, it not only improves the value and uptake of the data itself, in many cases it also creates new incentives for engagement and the necessary preconditions for the sustainability and continuation of a $\mathrm{CO}$.

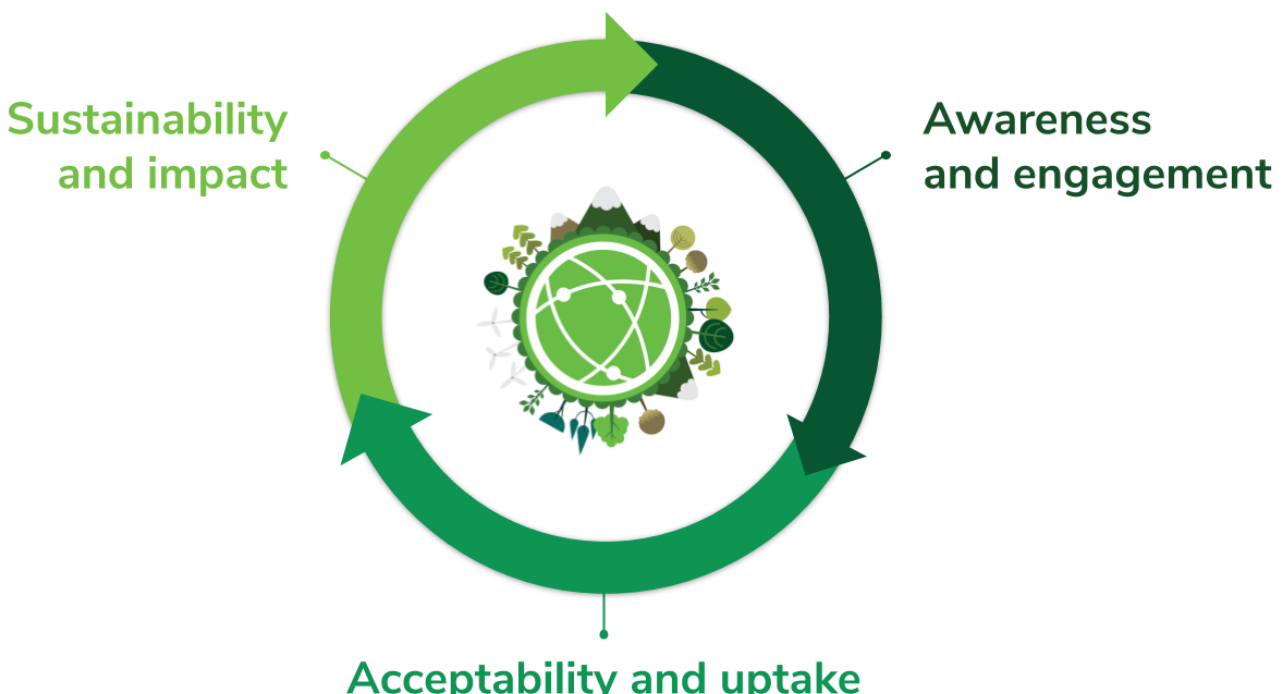

Figure 3. Reinforcing success cycle.

Hence, from the onset, it is critical to (1) build awareness and engage established, place-based communities and facilitate exchange across stakeholders; to (2) foster data quality and trust in data and technologies within context and for their intended use and deploy methods that ensure data quality as well as the use and accessibility of data; to (3) continuously demonstrate impact through impact stories and create value for all stakeholders; and to (4) consider initial project funding as seed-money and establish sustainability elements in the project design with the aim to establish the COs longer-term. Table 5 summarises specific actions to address these challenges. They mark areas where future COs can improve current practice and develop new best-practices.

Table 5: Actions to address the CO challenges and further strengthen the impact of the COs.

\begin{tabular}{|l|l|}
\hline \multicolumn{3}{|c|}{ Communication, co-design, community and network building } \\
\hline $\begin{array}{l}\text { Involve active place- } \\
\text { based communities } \\
\text { and community organ- } \\
\text { isations }\end{array}$ & $\begin{array}{l}\text { Collaborating with civil society and non-governmental organisations and } \\
\text { others can help to nurture community champions and local ambassadors } \\
\text { and to embed a CO locally, and longer term. Working with active com- } \\
\text { munities is also likely to generate the success stories needed to attract } \\
\text { other, less active communities, and scale up CO initiatives. A screening } \\
\text { process with resources is needed to identify the communities and other } \\
\text { key institutions to form an ecosystem that can support community-driven } \\
\text { observatories locally. }\end{array}$ \\
\hline $\begin{array}{l}\text { Engage with decision } \\
\text { makers, policy and } \\
\text { government agencies } \\
\text { early on }\end{array}$ & $\begin{array}{l}\text { Discussions on how to embed citizen generated data into the decision- } \\
\text { making cycle (from local to national planning and management) are es- } \\
\text { sential to reach policy acceptance. Include such plans and relevant part- } \\
\text { ners already in the project design and proposal phase (environmental } \\
\text { protection agencies, city councils, regional government agencies etc). }\end{array}$ \\
\hline
\end{tabular}


Table 5: Continued from the previous page.

\begin{tabular}{|c|c|}
\hline Collaborate with SMEs & $\begin{array}{l}\text { To explore the potential of CO data, services and tools for real life applic- } \\
\text { ations and services, collaborations with SMEs can help illuminate value } \\
\text { creation and market uptake beyond science and policy making. }\end{array}$ \\
\hline $\begin{array}{l}\text { Ensure strong and suit- } \\
\text { able communication } \\
\text { and facilitation across } \\
\text { stakeholders }\end{array}$ & $\begin{array}{l}\text { Deliberate communication and facilitation allows for efficient multi- } \\
\text { directional collaboration, translates information across stakeholders and } \\
\text { helps to build trust and alignment. Facilitating all-stakeholder design } \\
\text { as multi-lateral consultation or collaborative development helps to un- } \\
\text { derstand individual stakeholder needs as well as offers (and can help) } \\
\text { to address potentially contradictory goals. Multiple iterations increase } \\
\text { transparency, facilitate cooperation and create robust outcomes. }\end{array}$ \\
\hline Eng & $\begin{array}{l}\text { Engaging media outlets with the goals and outcomes of the CO, especially } \\
\text { via storytelling, helps to attract new participants to the specific CO but } \\
\text { also raise awareness of } \mathrm{CO} \text { and CS approaches more generally. }\end{array}$ \\
\hline ase CO capabil- & $\begin{array}{l}\text { Highlighting capabilities of a CO, its impacts and outcomes, e.g., in policy } \\
\text { making and environmental management, creates opportunities for col- } \\
\text { laboration and the re-use of data and platforms. This can strengthen } \\
\text { knowledge and awareness of the value of citizen generated data as well } \\
\text { as reduce barriers or lingering concerns for citizens themselves, the com- } \\
\text { munity, authorities and society at large. }\end{array}$ \\
\hline ccess and impact & $\begin{array}{l}\text { Telling CO's success stori } \\
\text { jectives and making tang } \\
\text { other stakeholders. }\end{array}$ \\
\hline \multicolumn{2}{|c|}{ Data quality and standards, integration and interoperability, accessibility and protection } \\
\hline $\begin{array}{l}\text { Describe and define } \\
\text { the purpose of } \\
\text { gathered data across } \\
\text { stakeholders }\end{array}$ & $\begin{array}{l}\text { This helps to address barriers and balance trade-offs between rigid sci- } \\
\text { entific methodologies and quality controls and the actual contexts and } \\
\text { diverse goals of stakeholders the data are collected by and intended for. } \\
\text { It also serves to explore the meaning of data quality and trust in data for } \\
\text { a wide range of stakeholders. }\end{array}$ \\
\hline $\begin{array}{l}\text { Document data quality } \\
\text { and adhere to existing } \\
\text { data standards }\end{array}$ & $\begin{array}{l}\text { Implementing quality standards will help COs gain acceptar } \\
\text { services will increase the uptake of data as well as improve } \\
\text { ility in larger systems, such as integration with GEOSS or th }\end{array}$ \\
\hline $\begin{array}{l}\text { Further develop se- } \\
\text { mantics for data } \\
\text { collection }\end{array}$ & $\begin{array}{l}\text { Describing the human dimension as part of data standards and metadata } \\
\text { descriptions (contributor/user descriptions and requirements/needs, } \\
\text { etc.) can help provide a more comprehensive picture of data, its potential } \\
\text { value and use. }\end{array}$ \\
\hline $\begin{array}{l}\text { ipants and } \\
\text { ers }\end{array}$ & $\begin{array}{l}\text { Training participants in the steps of data collection, while acknowledging } \\
\text { their needs, interests and motivations, is an important mechanism to en- } \\
\text { sure data quality, and increase trust and buy-in. This can be achieved, } \\
\text { amongst others, through DIY toolboxes, embedded and social learning } \\
\text { platforms, gamification, information feedback, or advice services. }\end{array}$ \\
\hline $\begin{array}{l}\text { Establish models to } \\
\text { balance privacy and } \\
\text { data protection re- } \\
\text { quirements with the } \\
\text { mandate for open } \\
\text { access data and trans- } \\
\text { parent data governance }\end{array}$ & $\begin{array}{l}\text { Creating specific CO data policies helps establish clear agreements on } \\
\text { what data can be shared, and when and how it can be used by others. } \\
\text { It helps address privacy and traceability issues of citizen-based contribu- } \\
\text { tions, dealing with personal and sensitive data and data protection meas- } \\
\text { ures while striving to allow open data access, so a broader audience can } \\
\text { create insight from the data. }\end{array}$ \\
\hline \multicolumn{2}{|r|}{ Technology transfer and business prototyping } \\
\hline $\begin{array}{l}\text { Build on and reuse } \\
\text { existing, open access } \\
\text { technologies }\end{array}$ & $\begin{array}{l}\text { Development efforts can build on open code and prior experiences and } \\
\text { focus on user feedback, and iteratively improve supportive technologies, } \\
\text { e.g., for sensing, data gathering, data sharing and visualisation, in order } \\
\text { to improve technology effectiveness and usability. }\end{array}$ \\
\hline $\begin{array}{l}\text { Consider and actively } \\
\text { tackle waste issues }\end{array}$ & $\begin{array}{l}\text { Waste produced by COs (e.g., the packaging, distribution, and disposal of } \\
\text { sensors) must be dealt with, and should be planned for from the outset. } \\
\text { Grassroots communities need to be supported especially where country } \\
\text { regulations are inconsistent. }\end{array}$ \\
\hline
\end{tabular}

Continued on the next page. 
Table 5: Continued from the previous page.

\begin{tabular}{|l|l|}
\hline $\begin{array}{l}\text { Calculate and commu- } \\
\text { nicate CO costs and be- } \\
\text { nefits }\end{array}$ & $\begin{array}{l}\text { A robust and comprehensive cost/benefit analysis has wide implications } \\
\text { for both the acceptability and sustainability of COs, also trying to doc- } \\
\text { ument non-commercial value. It can create a basis for decision-making } \\
\text { and a good case for incurring uptake and maintenance costs, e.g., by } \\
\text { public authorities. Maintenance costs after a CO has been set-up and the } \\
\text { technologies and methodologies have been created, should be considered } \\
\text { separately from the CO development costs. Value estimates of potential } \\
\text { CO products and services should also be considered, even though these } \\
\text { can be hard to quantify in advance. }\end{array}$ \\
\hline $\begin{array}{l}\text { Include business part- } \\
\text { ners to develop the } \\
\text { market potential of } \\
\text { COs }\end{array}$ & $\begin{array}{l}\text { A commercial partner can help turn CO efforts into tangible products } \\
\text { or services beyond the project funding by developing a sustainability } \\
\text { model, whereby a proof of concept can be turned into a launchable busi- } \\
\text { ness concept and funded by start-up, seed, or VC funding, creating links } \\
\text { and handovers to the next support mechanism. }\end{array}$ \\
\hline $\begin{array}{l}\text { Transfer business mod- } \\
\text { els }\end{array}$ & $\begin{array}{l}\text { Developing and handing over CO business model scenarios and } \\
\text { roadmaps allows for continuity, so initiatives are not automatically } \\
\text { dropped at the end of a funded project. }\end{array}$ \\
\hline
\end{tabular}

Linking with international frameworks and systems. COs can considerably increase their impact and uptake by linking with established international frameworks and groups. The intergovernmental GEO (building GEOSS), and the UN SDGs framework were considered specifically within the WeObserve project. Potential synergies with COs were explored and documented in several publications. The Lisbon Declaration [Masó and Fritz, 2020], produced by members of the Interoperability CoP, outlined the necessary steps to integrate CS data in the GEOSS catalogue, demonstrating the value of CS for EO, as well as providing recommendations to funding bodies to actively support this process. Two publications produced by members of the SDGs CoP have highlighted the potential of CS and COs for SDG monitoring [Fraisl et al., 2020; Fritz et al., 2019]. Table 6 summarises the main actions recommended to support future integration of $\mathrm{CO}$ and CS initiatives with these international systems.

Advancing the field through meta-collaboration and networks. One of the most powerful ways - to address the challenges faced by COs, put solutions into practice, and facilitate integration with international and intergovernmental frameworks - is to invest and participate in collaborative groups and networks that can reach beyond the individual CO projects (such as the WeObserve CoPs, the OGC CS Domain Working Group, the GEO CS group, $\mathrm{CSGP}^{15} \mathrm{CSA}^{16} \mathrm{ECSA}^{17}$ ACSA, ${ }^{18}$ etc.). WeObserve CoPs have gained recognition for establishing international practitioner groups and provide a successful model for spin-off CoPs. ${ }^{19}$ For example, the SDGs CoP engages CO/CS practitioners and researchers, NSOs and government officials, UN and other international agencies, and data and statistics communities in a dialogue for the integration of CS into the official SDG monitoring processes. Regarding GEOSS, CS associations or CoPs are needed to set

\footnotetext{
${ }^{14}$ European Open Science Cloud.

${ }^{15}$ Citizen Science Global Partnership.

${ }^{16}$ Citizen Science Association (U.S.A.).

${ }^{17}$ European Citizen Science Association.

${ }^{18}$ Australian Citizen Science Association.

${ }^{19} \mathrm{http}$ :/ / citizenscienceglobal.org/ projects.html\#csos.
} 
Table 6. Actions to integrate COs and CS with international systems.

\begin{tabular}{|c|c|}
\hline \multicolumn{2}{|c|}{ Actions needed to encourage the integration of CS and CO data and projects with... } \\
\hline \multicolumn{2}{|r|}{ GEO and GEOSS } \\
\hline Share resources & $\begin{array}{l}\text { Creating a federation of technical resources of CS and COs to host and share } \\
\text { services can help to amplify the interoperability of project data, create common } \\
\text { vocabularies and procedures that aggregate CS/CO data into bigger datasets, } \\
\text { share data quality tools. It can also provide centralised and trusted infrastruc- } \\
\text { ture, authorisation and tools to deploy and maintain CS campaigns. }\end{array}$ \\
\hline $\begin{array}{l}\text { Promote col- } \\
\text { laboration }\end{array}$ & $\begin{array}{l}\text { Enhancing collaboration between CS practitioners and formalised GEO mem- } \\
\text { ber groups and participant organisations, in coordination with the GEO Secret- } \\
\text { ariat can promote the potential of CS data as a data source that complements } \\
\text { remote sensing and traditional in-situ data, simplify the mechanism to include } \\
\text { CS data in GEOSS by connecting the CS federation directly to the GEOSS plat- } \\
\text { form, provide services that are appealing to citizens and citizen scientists as } \\
\text { well as enhance opportunities for citizen scientists to exploit GEOSS data. }\end{array}$ \\
\hline \multicolumn{2}{|r|}{ The UN Sustainable Development Goals } \\
\hline $\begin{array}{l}\text { Enable the up- } \\
\text { take of CS data }\end{array}$ & $\begin{array}{l}\text { Collaborate with national statistical offices (NSOs) to explore options to integ- } \\
\text { rate CS data streams into NSO practices, at the national level and with relevant } \\
\text { UN custodian agencies to create an environment that enables the uptake of CS } \\
\text { data, through building and maintaining infrastructures, capacities and key part- } \\
\text { nerships. }\end{array}$ \\
\hline $\begin{array}{l}\text { Elevate CS ini- } \\
\text { tiatives' capab- } \\
\text { ilities }\end{array}$ & $\begin{array}{l}\text { Support initiatives that could contribute to SDG monitoring to modify and im- } \\
\text { prove their data collection and analytical tools, data validation and interoper- } \\
\text { ability measures to ensure that the data comply with NSO requirements and for } \\
\text { their potential to be realised for SDG monitoring. }\end{array}$ \\
\hline $\begin{array}{l}\text { Disseminate } \\
\text { and support } \\
\text { best-practices }\end{array}$ & $\begin{array}{l}\text { Create an inventory of best practice examples and success stories and develop } \\
\text { further case studies where COs/CS data are used in innovative ways by NSOs } \\
\text { and disseminating these examples through appropriate channels. Further stim- } \\
\text { ulate and support SDG-relevant CS activities, at the local level, e.g., by creating } \\
\text { brokerage systems where CS practitioners can map their CS projects and data } \\
\text { against SDG indicator needs. }\end{array}$ \\
\hline $\begin{array}{l}\text { Align data pro- } \\
\text { tocols }\end{array}$ & $\begin{array}{l}\text { Identifying data quality criteria or data quality assurance procedures that can } \\
\text { align with requirements from NSOs and other government agencies. Invest- } \\
\text { igate the feasibility of aligning data collection methods across projects with } \\
\text { global definitions to implement internationally comparable methods and data } \\
\text { for global level SDG reporting. }\end{array}$ \\
\hline $\begin{array}{l}\text { Secure in- } \\
\text { vestment and } \\
\text { engagement }\end{array}$ & $\begin{array}{l}\text { Secure investment and encourage the development of business cases linked to } \\
\text { the sustainability of the CO/CS initiatives to maintain essential technical infra- } \\
\text { structures and the engagement of citizens for SDG monitoring longer-term. }\end{array}$ \\
\hline
\end{tabular}

up the governance structures necessary to effectively run a federation of technical infrastructures for CS, train CS projects on GEOSS principles, or help close the gap between citizens and GEOSS.

Fostering a trustworthy and enabling environment for COs. WeObserve has helped to better understand what factors constitute an enabling environment for COs, that supports the 'Triangle of Trust'. In the following description, we align with the broader and encompassing use of the term enabling environment [Amjad et al., 2015; Thindwa, Monico and Reuben, 2003] as a "set of interrelated conditions" [Thindwa, Monico and Reuben, 2003, p. 4], as opposed to a narrower use of it referring solely to legal/policy frameworks. Hence, an enabling environment for COs can be described as the sum of conditions that enable a $\mathrm{CO}$ to start, function and sustain its activities to deliver value and impact across multiple stakeholders. The factors that build up such a trustworthy and enabling 
environment for COs are mainly comprised of an (1) active and engaged network of stakeholders and place-based communities, with linkage to farther reaching networks and communities of practice; (2) a set of relevant skills, capacity building, training and knowledge sharing capabilities within the $\mathrm{CO}$; (3) suitable and reliable technology, integrated data infrastructures, transparent data policies, common vocabularies and implementable web standards in support of the $\mathrm{CO}$; and (4) suitable legal, policy and funding frameworks around the $\mathrm{CO}$, that allow for flexibility and outreach, and encourage sustainability, impact and value delivery. It is key to the effective creation of such an environment that all actors and stakeholders contribute and support the aims of a $\mathrm{CO}$.

Advancing the $\mathrm{CO}$ concept through Horizon Europe
The recently launched EU research and innovation framework programme Horizon Europe (2021-2027) is centred around the main objective of generating knowledge and supporting the uptake of innovative solutions to address global challenges, including climate change and the SDGs [European Commission, 2019a; European Commission, 2019c]. Within Horizon Europe, numerous opportunities arise to further advance the concept of COs, but also for COs to serve as a mechanism to support the delivery of the framework's ambition.

Future CO development can benefit from Horizon Europe's orientation towards missions and its focus on creating impact for society, policy making and relevance for a wide range of European citizens [European Commission, 2019b; Mazzucato, 2019]. COs can be strategically embedded and progressed to help achieve the aim of widening participation and relating EU's research and innovation better to society and citizens' needs. The aim of enhancing the European research and innovation system through CS, Responsible Research and Innovation (RRI) and Open Science directly support the implementation of COs, based on CO characteristics. Furthermore, a wide range of thematic clusters in Pillar II allow further growth and wider application of the $\mathrm{CO}$ concept, from, e.g., operationalising air quality observatories for pollution monitoring (Cluster 1: Health); coupling EO from space with citizen-powered ground-truthing (Cluster 4: Digital, Industry and Space); to broader activities aimed at providing solutions for natural capital conservation, and fostering climate neutral and resilient societies (Cluster 5: Climate, Energy and Mobility, and Cluster 6: Food, Bioeconomy, Natural Resources, Agriculture and Environment). The Horizon Europe focus on creating research and data infrastructures as well as spurring innovation and new markets can enable further consideration of technical and data related $\mathrm{CO}$ requirements as well as supporting COs in developing new business models and value chain creation.

Vice versa, the $\mathrm{CO}$ concept now provides a suitable and well tested mechanism that can support the delivery of the Horizon Europe ambition across the entire R\&I programme. COs offer opportunities for citizens' and stakeholder involvement and participation. They are well positioned to address socio-ecological challenges, by addressing data gaps and EO ground-truthing, facilitating multi-stakeholder processes, creating circular information flows to support decision-making as well as supporting evidence-based policies. Furthermore, COs show great potential to help monitor and achieve the SDGs. 
Here, we offer several recommendations for setting up funding conditions to improve the opportunities for COs in Horizon Europe as well as advance COs in service of Horizon Europe goals:

- Support strong communication and media plans, as well as appropriate consortium composition that secures the engagement of policy, stakeholders, place-based communities and community organisations from the start.

- Strengthen networks and build sustainable infrastructures, such as

- Supporting established networks and CoPs and linking relevant actors (e.g., ECSA, UN, GEO, OGC, UNESCO, etc.),

- Creating a permanent e-infrastructure to federate CS projects, integrate CS data, host and share services, as well as connecting the federation to the EOSC and to the GEOSS platform, and

口 Promoting open source software, shared code bases, and sustainable hardware.

- Offer innovative funding schemes, that

- Are flexible and allow for iteration and co-design,

- Provide innovative follow-up funding and support of governance transitions when projects meet specific targets and demonstrate impact,

- Support the link and transition into national funding schemes for local continuation, and

- Offer tenders to develop proof-of-concept applications into reliable open source tools.

Building on strengths
This paper summarises recent developments around the concept and implementation of COs within the European funding context, highlighting cross-cutting impacts and realised changes from micro- to macro-level from four $\mathrm{CO}$ projects, as well as addressing $\mathrm{CO}$ challenges and opportunities. The wide range of solution-focused activities, collaborations and resources that WeObserve has generated and the collated insights from the collective legacy and experiences gained, have helped to amplify the successes achieved, as well as compare the lessons learnt. Thus, WeObserve also offered a glimpse of the continuity and effort required to establish COs long-term, and to be able to draw constructive conclusions from them. We have also looked at how the projects, most of which have now ended, can inform the development of more effective COs in the future and to refine what an 'enabling environment' for COs would look like.

The paper further demonstrates that COs are emerging as a viable approach for data collection, evidence-based insights, as well as multi-stakeholder collaborations (citizens/policy makers/scientists), a core strength of COs in light of the socio-ecological problems facing communities around the world. Such a combination of diverse stakeholder groups, technologies, data users, and levels of interaction and application - from the SDGs to the very local - can be a strong enabler of social and data innovations. 
Based on these reflections, the paper puts forward recommendations to advise practitioners of future COs, as well as to inform forthcoming funding avenues such as Horizon Europe, highlighting how CO capabilities and strengths align with the EC's latest strategy. Funding calls can be refined to foster the advancement of the $\mathrm{CO}$ concept, and to reflect the notion of COs as a vibrant academic and practice-focused concept with the potential to create positive change and public engagement at a local and global scale. Since 2012, COs have evolved considerably. With suitable funding in place, COs will be able to overcome many of the lingering challenges. Europe can continue to play an enabling and innovative role in tackling socio-ecological challenges in the future, not only in Europe, but globally, by continuing the advancement of COs as an inclusive, evidence-based and operational mechanism for addressing such challenges.

\section{Acknowledgments}

The WeObserve project has received funding from the European Union's Horizon 2020 research and innovation programme under grant agreement No. 776740. We also thank the four CO projects LandSense (grant agreement No. 689812), Ground Truth 2.0 (grant agreement No. 689744), GROW Observatory (grant agreement No. 690199) and Scent (grant agreement No. 688930), as well as the COS4CLOUD project (grant agreement No. 863463) for providing valuable inputs.

\section{References}

Ajates, R., Hager, G., Georgiadis, P., Coulson, S., Woods, M. and Hemment, D. (2020). 'Local Action with Global Impact: The Case of the GROW Observatory and the Sustainable Development Goals'. Sustainability 12 (24), p. 10518. https://doi.org/10.3390/su122410518.

Ajates, R., Woods, M., Gulari, N., Hemment, D., Georgiadis, P., Hager, G., van der Velden, N., Verrall, S. and Burton, V. (2020). 'From contributory to collegial: a model to foster citizen-led open data innovation in citizens'. In: Poster session presented at European Citizen Science Association Conference (Trieste, Italy).

Amjad, U., Ojomo, E., Downs, K., Cronk, R. and Bartram, J. (2015). ‘Rethinking sustainability, scaling up and enabling environment: a framework for their implementation in drinking water supply'. Water 7 (12), pp. 1497-1514. https://doi.org/10.3390/w7041497.

Anhalt-Depies, C., Stenglein, J. L., Zuckerberg, B., Townsend, P. A. and Rissman, A. R. (2019). 'Tradeoffs and tools for data quality, privacy, transparency and trust in citizen science'. Biological Conservation 238, p. 108195. https://doi.org/10.1016/j.biocon.2019.108195.

Assumpção, T. H., Jonoski, A., Theona, I., Tsiakos, C., Krommyda, M., Tamascelli, S., Kallioras, A., Mierla, M., Georgiou, H. V., Miska, M., Pouliaris, C., Trifanov, C., Cimpan, K. T., Tsertou, A., Marin, E., Diakakis, M., Nichersu, I., Amditis, A. J. and Popescu, I. (2019). 'Citizens' campaigns for environmental water monitoring: lessons from field experiments'. IEEE Access 7, pp. 134601-134620. https://doi.org/10.1109/access . 2019.2939471.

Bonney, R., Ballard, H., Jordan, R., McCallie, E., Phillips, T., Shirk, J. and Wilderman, C. C. (2009). Public Participation in Scientific Research: Defining the Field and Assessing Its Potential for Informal Science Education. A CAISE Inquiry Group Report. Washington, D.C., U.S.A.: Center for Advancement of Informal Science Education (CAISE). URL: http://www . informalscience.org/public-p articipation-scientific-research-defining-field-and-assessing-its-p otential-informal-science. 
Capellan, S. (2020). Deliverable 4.7. Demo 3: forest and habitat monitoring using innovative technologies II. LandSense project.

https://doi.org/10.5281/zenodo. 4452753.

Ciravegna, F., Huwald, H., Lanfranchi, V. and Wehn de Montalvo, U. (2013). 'Citizen observatories: the WeSenseIt vision'. In: Proceedings of the Infrastructure for Spatial Information in the European Community (INSPIRE 2013) (Florence, Italy). URL: https://inspire.ec.europa.eu/events/conferences/inspire_20 13/pdfs/27-06-2013_ROOM-6_14.00\%20-\%2016.00_205-Uta \%20Wehn \%20de\%20M ontalvo_Uta-Wehn-de-Montalvo.pdf.

Domian, D. and Hager, G. (2019). 'Observing the environment — challenges \& opportunities in citizen science'. Zenodo. https://doi .org/10.5281/ZENODO . 3981179. (Visited on 15th October 2020).

Eitzel, M. V., Cappadonna, J. L., Santos-Lang, C., Duerr, R. E., Virapongse, A., West, S. E., Kyba, C. C. M., Bowser, A., Cooper, C. B., Sforzi, A., Metcalfe, A. N., Harris, E. S., Thiel, M., Haklay, M., Ponciano, L., Roche, J., Ceccaroni, L., Shilling, F. M., Dörler, D., Heigl, F., Kiessling, T., Davis, B. Y. and Jiang, Q. (2017). 'Citizen science terminology matters: exploring key terms'. Citizen Science: Theory and Practice 2 (1), pp. 1-20. https://doi .org/10.5334/cstp. 96.

European Commission (2019a). Horizon Europe - investing to shape our future.

URL: https://ec.europa.eu/info/sites/info/files/research_and_innovat ion/strategy_on_research_and_innovation/presentations/horizon_europe _en_investing_to_shape_our_future.pdf.

- (2019b). Missions in Horizon Europe.

URL: https://ec.europa.eu/info/horizon-europe-next-research-and-inno vation-framework-programme/missions-horizon-europe_en.

- $(2019 \mathrm{c})$. Orientations towards the first Strategic Plan for Horizon Europe. URL: https://ec.europa.eu/info/sites/info/files/research_and_innovat ion/strategy_on_research_and_innovation/documents/ec_rtd_orientation s-he-strategic-plan_122019.pdf.

Fraisl, D., Campbell, J., See, L., Wehn, U., Wardlaw, J., Gold, M., Moorthy, I., Arias, R., Piera, J., Oliver, J. L., Masó, J., Penker, M. and Fritz, S. (2020).

'Mapping citizen science contributions to the UN sustainable development goals'. Sustainability Science 15 (6), pp. 1735-1751. https://doi.org/10.1007/s11625-020-00833-7.

Fritz, S., See, L., Carlson, T., Haklay, M., Oliver, J. L., Fraisl, D., Mondardini, R., Brocklehurst, M., Shanley, L. A., Schade, S., Wehn, U., Abrate, T., Anstee, J., Arnold, S., Billot, M., Campbell, J., Espey, J., Gold, M., Hager, G., He, S., Hepburn, L., Hsu, A., Long, D., Masó, J., McCallum, I., Muniafu, M., Moorthy, I., Obersteiner, M., Parker, A. J., Weisspflug, M. and West, S. (2019). 'Citizen science and the United Nations Sustainable Development Goals'. Nature Sustainability 2 (10), pp. 922-930. https://doi.org/10.1038/s41893-019-0390-3.

Gabrys, J., Pritchard, H. and Barratt, B. (2016). 'Just good enough data: figuring data citizenships through air pollution sensing and data stories'. Big Data $\mathcal{E}$ Society 3 (2), p. 205395171667967 . https://doi.org/10.1177/2053951716679677.

Gharesifard, M., Wehn, U. and van der Zaag, P. (2019). 'Context matters: a baseline analysis of contextual realities for two community-based monitoring initiatives of water and environment in Europe and Africa'. Journal of Hydrology 579, p. 124144. https://doi .org/10.1016/j. jhydrol.2019.124144. 
Gold, M., Wehn, U., Bilbao, A. and Hager, G. (2020). WeObserve D2.4 final EU citizen observatories landscape report: addressing the challenges of awareness, acceptability and sustainability. https://doi.org/10.5281/zenodo. 4472670.

Gold, M. (2018). ‘D2.1 EU citizen observatories landscape report - frameworks for mapping existing $\mathrm{CO}$ initiatives and their relevant communities and interactions'. Zenodo. https://doi.org/10.5281/ZENOD0. 3670895.

Gold, M. and Wehn, U. (2020). 'Mission sustainable: fostering an enabling environment for sustainable Citizen Observatories. WeObserve policy brief 2'. Zenodo. https://doi.org/10.5281/ZENODO. 4001672.

Grainger, A. (2017). 'Citizen observatories and the new earth observation science'. Remote Sensing 9 (2), p. 153. https://doi.org/10.3390/rs9020153.

GROW (2020a). GROW observatory - summary report. URL: https: //growobservatory . org/GROW-Summary-Report.pdf.

- (2020b). What is the GROW observatory? URL: https: //growobservatory . org/.

Hecker, S., Wicke, N., Haklay, M. and Bonn, A. (2019). 'How does policy conceptualise citizen science? A qualitative content analysis of international policy documents'. Citizen Science: Theory and Practice 4 (1), p. 32. https://doi.org/10.5334/cstp. 230.

Iglesias, R. (2013). 'Citizens' observatories for monitoring the environment: a commission perspective'. In: Proceedings of workshop on citizen's involvement in environmental governance. Arlon, Belgium: Directorate General Research and Innovation, European Commission.

LandSense (2019). Citizen observatories. A voice for citizens in environmental monitoring. URL: https://www. weobserve.eu/wp-content/uploads/2019/10/p olictb_landsense_official_20190913_updated.pdf.

LandSense, Scent, Ground Truth 2.0 and GROW (2018). Common dissemination booster: building a citizen centric ecosystem to monitor land, the environment and climate change.

Liu, H.-Y., Grossberndt, S. and Kobernus, M. (2017). 'Citizen science and citizens' observatories: trends, roles, challenges and development needs for science and environmental governance'. In: Mapping and the citizen sensor. Ed. by G. M. Foody, L. See, S. Fritz, C. C. Fonte, P. Mooney, A.-M. Olteanu-Raimond and V. Antoniou. London, U.K.: Ubiquity Press, pp. 351-376.

https://doi.org/10.5334/bbf.o.

Liu, H.-Y. and Kobernus, M. (2017). 'Citizen science and its role in sustainable development: status, trends, issues and opportunities'. In: Analyzing the role of citizen science in modern research. Advances in knowledge acquisition, transfer and management. Ed. by L. Ceccaroni and J. Piera. Hershey, PA, U.S.A.: IGI Global, pp. 147-167. https://doi .org/10.4018/978-1-5225-0962-2.ch007.

Liu, H.-Y., Kobernus, M., Broday, D. and Bartonova, A. (2014). 'A conceptual approach to a citizens' observatory - supporting community-based environmental governance'. Environmental Health 13 (1), 107. https://doi.org/10.1186/1476-069x-13-107.

Locritani, M., Merlino, S. and Abbate, M. (2019). 'Assessing the citizen science approach as tool to increase awareness on the marine litter problem'. Marine Pollution Bulletin 140, pp. 320-329.

https://doi.org/10.1016/j.marpolbul.2019.01.023.

Mahajan, S., Kumar, P., Pinto, J. A., Riccetti, A., Schaaf, K., Camprodon, G., Smári, V., Passani, A. and Forino, G. (2020). 'A citizen science approach for enhancing public understanding of air pollution'. Sustainable Cities and Society 52, p. 101800. https://doi.org/10.1016/j.scs.2019.101800. 
Manzoni, M., Vohland, K., Göbel, C., Pruse, B. and Schade, S. (2019). Citizen science strategies in Europe - preliminary findings from the pan-European survey of citizen science strategies and initiatives in Europe as part of a joint initiative of the COST ACTION 15212 and the JRC discussed in Cèsis, Latvia, 4th June 2019.

https://doi .org/10.7479/MYW2-9584. (Visited on 15th October 2020).

Masó, J. and Fritz, S. (2020). 'EuroGEO 2019 citizen science roadmap — "Lisbon declaration"'. Zenodo. https://doi.org/10.5281/ZENODO. 3946506. (Visited on 15th October 2020).

Masó, J. and Wehn, U. (2020). 'A roadmap for citizen science in GEO - the essence of the Lisbon declaration. WeObserve policy brief 1'. Zenodo. https://doi.org/10.5281/ZENOD0.4001683.

Mazumdar, S., Lanfranchi, V., Ireson, N., Wrigley, S., Bagnasco, C., Wehn, U., McDonagh, R., Ferri, M., McCarthy, S., Huwald, H. and Ciravegna, F. (2016). 'Citizens observatories for effective earth observations: the WeSenseIt approach'. Environmental Scientist 25 (2), pp. 56-61.

URL: https://www . the-ies .org/resources/they-walk-among-us-rise.

Mazzucato, M. (2019). Governing missions in the European Union. Independent expert report. European Commission.

URL: https://ec.europa.eu/info/sites/info/files/research_and_innovat ion/contact/documents/ec_rtd_mazzucato-report-issue2_072019.pdf.

McGlade, J. (2009). Global citizen observatory - the role of individuals in observing and understanding our changing world. Annual earthwatch lecture - Citizen science, Oxford, U.K., 16th February 2009. URL: http://www . eea. europa. eu/media/spe eches/global-citizen-observatory-the-role-of-individuals-in-observi ng-and-understanding-our-changing-world.

Moorthy, I., Stickler, T., Olteanu-Raimond, A.-M., Schrammeijer, B. and Schultz, M. (2020). 'Deliverable 4.1 demo 1: cost reduction and data conflation in monitoring land change I'. LandSense project. Zenodo. https://doi.org/10.5281/ZENODO . 3670904.

Mrkajić, V. (2020). 'Deliverable 4.6 demo 2: monitoring agricultural land use and provision of value-added agricultural services II'. LandSense project. Zenodo. https://doi.org/10.5281/ZENODO .4452742.

Roman, L. A., Scharenbroch, B. C., Östberg, J. P. A., Mueller, L. S., Henning, J. G., Koeser, A. K., Sanders, J. R., Betz, D. R. and Jordan, R. C. (2017). 'Data quality in citizen science urban tree inventories'. Urban Forestry \& Urban Greening 22, pp. 124-135. https://doi.org/10.1016/j .ufug. 2017.02.001.

Sauermann, H., Vohland, K., Antoniou, V., Balázs, B., Göbel, C., Karatzas, K., Mooney, P., Perelló, J., Ponti, M., Samson, R. and Winter, S. (2020). 'Citizen science and sustainability transitions'. Research Policy 49 (5), p. 103978. https://doi.org/10.1016/j.respol.2020.103978.

SCENT (2020a). Evaluation of SCENT toolbox. SCENT consortium. URL: https://www . weobserve.eu/wp-content/uploads/2020/08/SCENT-D7_4 _V1_Evaluation-of-SCENT-Toolbox.pdf.

- (2020b). Report on outcomes of the field trials in Danube delta. SCENT consortium. URL: https://www . weobserve.eu/wp-content/uploads/2020/08/SCENT-D7_2 _V1_-Report-on-outcomes-of-the-field-trials-in-Danube-Delta.pdf.

- (2020c). Report on outcomes of the field trials in Kifisos. SCENT consortium. URL: https://www. weobserve. eu/wp-content/uploads/2020/08/SCENT-D7_3V1_Report-on-outcomes-of-the-field-trials-in-Kifisos.pdf.

- (2020d). Smart Toolbox for Engaging Citizens into a People-Centric Observation Web (SCENT). URL: https://scent-project.eu/. 
Serret, H., Deguines, N., Jang, Y., Lois, G. and Julliard, R. (2019). ‘Data quality and participant engagement in citizen science: comparing two approaches for monitoring pollinators in France and South Korea'. Citizen Science: Theory and Practice 4 (1), p. 22. https: //doi .org/10.5334/cstp. 200.

Thindwa, J., Monico, C. and Reuben, W. (2003). Enabling environments for civic engagement in PRSP countries. Washington, DC, U.S.A.: World Bank. URL: http://documents1. worldbank.org/curated/en/301441468762908841/p df/279920PAPER0sdn82.pdf.

Tsiakos, C., Krommyda, M., Kopsinis, Y., Amditis, A., Tsertou, A., Jonoski, A., Popescu, I. and Assumpcao, T. (2019). 'Improved LC/LU maps and flood models through crowdsourced information'. Zenodo. https://doi.org/10.5281/ZENODO . 3524901.

Van Es, M., Guijt, I. and Vogel, I. (2015). Theory of change thinking in practice. The Hague, The Netherlands: Hivos. URL: https : //www . openupcontracting . org/a ssets/2017/09/Hivos-ToC-guidelines-2015.pdf.

Wehn, U. (2018). 'Impact and value of citizen observatories for governance'. In: Launch workshop (Geneva, Switzerland, 6th June 2018).

Wehn, U., Gharesifard, M., Anema, K., Alfonso, L. and Mazzoleni, M. (2019). Initial validation and socio-economic impacts report (initial submission). Ground truth 2.0 project deliverable D1.11. Delft, The Netherlands.

Wehn, U., Gharesifard, M. and Bilbao, A. (2020). D2.2: report on IA methods adapted to CS. Deliverable report D2.2 of project H2020 MICS (grant agreement No. 824711).

Wehn, U., Pfeiffer, E., Gharesifard, M., Alfonso, L. and Anema, K. (2020). Updated validation and socio-economic impacts report. Ground truth 2.0 project deliverable D1.12. Delft, The Netherlands.

Wehn, U., Pfeiffer, E., Gharesifard, M., Anema, K. and Remmers, M. (2017). Methodology for validation and impact assessment. Ground truth 2.0 project deliverable D1.10. Delft, The Netherlands.

Wehn, U., McCarthy, S., Lanfranchi, V. and Tapsell, S. (2015). 'Citizen observatories as facilitators of change in water governance? Experiences from three European cases'. Environmental Engineering and Management Journal 14 (9), pp. 2073-2086. https://doi.org/10.30638/eemj.2015.222.

Wiggins, A., Newman, G., Stevenson, R. D. and Crowston, K. (2011). 'Mechanisms for data quality and validation in citizen science'. In: 2011 IEEE seventh international conference on e-science workshops (Stockholm, Sweden, 5th-8th December 2011). IEEE, pp. 14-19. https://doi.org/10.1109/esciencew.2011.27.

Woods, M., Ajates, R., Gulari, N., Burton, V. J., van der Velden, N. K. and Hemment, D. (2019). GROW observatory: mission outcomes. Dundee, U.K. https://doi.org/10.20933/100001130.

Woods, M., Cobley, A. and GROW consortium (2020). GROW soil moisture data. Dundee, U.K. https://doi.org/10.15132/10000156.

Xaver, A., Zappa, L., Rab, G., Pfeil, I., Vreugdenhil, M., Hemment, D. and Dorigo, W. A. (2019). 'Evaluating the suitability of the consumer low-cost Parrot Flower Power soil moisture sensor for scientific environmental applications'. Preprint. https://doi.org/10.5194/gi-2019-38. (Visited on 14th October 2020). 
Zappa, L., Forkel, M., Xaver, A. and Dorigo, W. (2019). 'Deriving field scale soil moisture from satellite observations and ground measurements in a hilly agricultural region'. Remote Sensing 11 (22), p. 2596. https://doi.org/10.3390/rs11222596.

Zappa, L., Woods, M., Hemment, D., Xaver, A. and Dorigo, W. (2020). 'Evaluation of remotely sensed soil moisture products using crowdsourced measurements'. In: Eighth international conference on remote sensing and geoinformation of the environment (RSCy2020) (Paphos, Cyprus, 26th August 2020). Ed. by K. Themistocleous, S. Michaelides, V. Ambrosia, D. G. Hadjimitsis and G. Papadavid. SPIE, p. 88. https://doi.org/10.1117/12.2571913. Systems Analysis. She develops participatory approaches to science and understanding systems including citizen science, serious games, social simulations and participatory systems modelling. She led the WeObserve project from 2019-2021 and was/is part of the H2020 GROW Observatory, EU-Citizen.Science and FRAMEwork projects. She holds a master's degree in System Dynamics, a MSc in Business Administration and a magister degree (univ.) in Art and Design Education. E-mail: hager@iiasa.ac.at.

Margaret Gold is Coordinator of the Citizen Science Lab at the University of Leiden. Before that, she was a Project Officer at the European Citizen Science Association, involved in the WeObserve, LandSense, and EU-Citizen.Science projects. She previously worked at the Natural History Museum, London and within the Citizen Cyberlab project. She holds an MBA from the Rotterdam School of Management and an Honours BA in International Relations from the University of Windsor, Canada. E-mail: m.gold@biology.leidenuniv.nl.

Uta Wehn is Associate Professor of Water Innovation Studies and acting Chair of the Knowledge \& Capacity Development group at IHE Delft. She is a social scientist with a background in ICTs, drawing on more than 20 years of industrial, research and international development experience. Her work at the intersection of data and knowledge co-creation, digital innovations and water and environment focuses on the social dynamics of innovation and how to harness digital transformations for participatory environmental governance and sustainable development. E-mail: u.wehn@un-ihe.org.

Raquel Ajates is a Carasso Foundation Research Fellow at the Universidad Nacional de Educación a Distancia, researching seed policies and open-source alternatives to the privatisation and digitalisation of seed material. She is also a Research Associate at University of Dundee, where she worked on the H2020 WeObserve and GROW Observatory projects. Before that, she was a Teaching Fellow at the Interdisciplinary Food System Teaching and Learning programme in the Centre for Food Policy at City University of London, where she completed her PhD in Food Policy. E-mail: r.ajatesgonzalez@dundee.ac.uk. 
Linda See is a Senior Research Scholar at the International Institute for Applied Systems Analysis. She has a PhD in computational geography from the University of Leeds, an MSc in climatology from McMaster University and a BSc in physical geography and environmental management from the University of Toronto. Her current interests include the combination of land use/land cover and citizen science as well as methods of citizen science quality assurance.

E-mail: see@iiasa.ac.at.

Mel Woods is Professor of Creative Intelligence at University of Dundee. Her expertise and research interests are at the intersection of creativity, technology, action-research and social innovation. She has formalised creative intelligence and sustained a critical enquiry into how data and technology can support decision-making and change for societal challenges, most recently through environmental and pollution monitoring in citizen science. She has established an international portfolio of competitive, peer reviewed, funded research leadership. E-mail:m.j.woods@dundee.ac.uk.

Chrysovalantis (Valantis) Tsiakos is a member of the Smart Integrated Systems \& Communication Team of the I-SENSE group at the Institute of Communication and Computer Systems. His studies focus on Urban Planning and Regional Development, Geoinformatics and Earth Observation. He has been involved in various EU funded projects, emphasising on the application of information systems in the environmental sector. His scientific interests include: spatial data infrastructures, remote sensing, image processing, standardisation, environmental applications, citizen science and crowdsourcing. E-mail: valantis.tsiakos@iccs.gr.

Joan Masó is a researcher in CREAF, leading group on geospatial interoperability, GIS, remote sensing . Active member of the Open Geospatial Consortium (editor WMTS standard and chair of the ILAF Forum), Gardels gold medal in 2019. Coordinator or participant in projects related to the GEOSS development (FP7 GeoViQua, H2020 ConnectinGeo, ECOPOTENTIAL ERA-PLANET and e-shape) and participant in Citizen Observatory development projects H2020 GroundTruth 2.0, H2020 WeObserve, H2020 COS4Cloud and ESA CSEOL-Phenotandem. Senior member of IEEE and council member of ISDE. E-mail: joan.maso@uab.cat.

Dilek Fraisl is a research scholar at IIASA. Her interests include the SDGs, citizen science and the use of new data sources for SDG monitoring. She is chair of the WeObserve SDGs \& Citizen Science Community of Practice" that fosters collaboration across the global citizen science, data and statistics communities. She co-chairs the Citizen Science Global Partnership SDGs \& Citizen Science Maximization Group, and is a member of the Sustainable Solutions Development Network - Thematic Research Network on Data and Statistics (SDSN TReNDS). E-mail: fraisl@iiasa.ac.at.

Inian Moorthy works at the International Institute for Applied Systems Analysis and led the H2020 LandSense project. His research interests include quantitative remote sensing, citizen science, and crowdsourcing mechanisms to complement Earth Observation datasets and processing chains. Dr. Moorthy received his PhD in the field of Earth \& Space Science from York University in Toronto, Canada. E-mail: moorthy@iiasa.ac.at. 
Dahlia Domian is a project officer at IIASA and coordinates and monitors projects and provides research support and development for scientific initiatives. She managed the WeObserve project from 2017-2019. Before IIASA, she worked as a consultant for several U.S.-based firms focused on financial inclusion and conflict management. She was a Fulbright Scholar in Brazil and holds an MA in international development from the Fletcher School of Law and Diplomacy at Tufts University. E-mail: domian@iiasa.ac.at.

Steffen Fritz is the IIASA Strategic Initiatives Program Director and a senior researcher in the Novel Data Ecosystems Research Group. He is the initiator of Geo-Wiki.org, a global land cover and land use validation tool to investigate and reduce the uncertainties in global land cover data through citizen science. Besides others, he was the coordinator (PI) of the ERC funded CrowdLand and H2020 funded LandSense and WeObserve projects. He worked at the JRC and has a PhD in Geography from the University of Leeds. E-mail: fritz@iiasa.ac.at.

\section{How to cite}

Hager, G., Gold, M., Wehn, U., Ajates, R., See, L., Woods, M., Tsiakos, C., Masó, J., Fraisl, D., Moorthy, I., Domian, D. and Fritz, S. (2021). 'Onto new horizons: insights from the WeObserve project to strengthen the awareness, acceptability and sustainability of Citizen Observatories in Europe'. JCOM 20 (06), A01. https://doi.org/10.22323/2.20060201. 